\title{
Green tea moisturizer improves skin hydration in elderly
}

\author{
Oentarini Tjandra*, Linda J Wijayadi**, and Marcella E Rumawas***
}

\begin{abstract}
\section{BACKGROUND}

Dry skin is a major skin health problem in elderly. Green tea, which has an antioxidant effect, has recently been used as an active ingredient in moisturizing creams; yet the effect has not been well studied. This study compares the skin hydration effect of green tea and vitamin E moisturizer among elderly.
\end{abstract}

\section{METHODS}

This quasi-experimental study involved 60 elderly living in Tresna Werda Budi Mulia 4 Social Institution, Jakarta. Using the Runve HL 611 skin analyzer, skin capacitance was measured prior to experiment and every following week during the 5-week application of green tea and vitamin E skin moisturizer on both forearms. The consecutive measurement data were analyzed using Generalized Estimating Equation to compare the relative changes in skin hydration between the two moisturizer groups over 5 weeks of intervention.

\section{RESULTS}

The green tea moisturizer showed more significant increases in skin hydration level than the vitamin E moisturizer at all measurement sites on right arm and proximal left $\operatorname{arm}(\mathrm{p}=0.021)$, and medial and distal left $\operatorname{arm}(\mathrm{p}=$ $0.034)$. Skin hydration levels significantly changed over time at proximal $(\mathrm{p}=0.021)$, medial $(\mathrm{p}=0.006)$ and distal $(\mathrm{p}=0.006)$ right arm, and medial left $\operatorname{arm}(\mathrm{p}=0.021)$. A parallel trend of skin hydration improvements for both moisturizer groups indicated no correlation between the moisturizer type and the duration of usage $(\mathrm{p}>0.05)$ in all measurement locations. No side effects were observed during application period in both groups.

\section{CONCLUSION}

Routine use of a moisturizer containing green tea may improve skin hydration in elderly.

Keywords: Green tea moisturizer, vitamin E, skin hydration, elderly

\section{*Pharmacology Department}

Faculty of Medicine

Tarumanagara University

**Dermatovenereology Department

Faculty of Medicine

Tarumanagara University

***Public Health Department

Faculty of Medicine

Tarumanagara University

\section{Correspondence:}

dr. Oentarini Tjandra, M.Biomed, MPd. Ked

Department of Pharmacology

Faculty of Medicine

Tarumanagara University

Jl. LetJen. S. Parman No. 1 Grogol

Jakarta Barat 11440

Email: uunfang@gmail.com

Fax:+6221-5663126

Date of first submission, July 14, 2017

Date of final revised submission,

February 6, 2018

Date of acceptance, February 11, 2018

This open access article is distributed under a Creative Commons AttributionNon Commercial-Share Alike 4.0

International License

Cite this article as: Tjandra $\mathrm{O}$, Wijayadi LJ, Rumawas ME. Green tea moisturizer improves skin hydration in elderly. Univ Med 2018;37:3-12. doi: 10.18051

/UnivMed.2018.v37.3-12 


\section{INTRODUCTION}

The skin is the outermost and largest organ of the human body, while one of its major roles is as a protective barrier against microorganisms and as the body's temperature regulator. Skin dryness increases the risk of developing several skin diseases, such as atopic dermatitis, irritant contact dermatitis, allergic contact dermatitis, ichthyosis, and psoriasis. ${ }^{(1)}$

The protective function of the skin is primarily performed by the epidermis, of which the stratum corneum is the outermost part.(2) The stratum corneum is a dynamic structure that continuously responds to various daily exogenous factors. The epidermal layer of the skin protects the body against many external stressors including physical (mechanical, thermal, ultraviolet rays) and chemical (solvents, surfactants, xenobiotics). ${ }^{(3)}$ It also protects the skin from being dehydrated through transepidermal water loss (TEWL). ${ }^{(4)}$

Every year, the older population in Indonesia increases in number. Statistics for 1980 recorded seven million older individuals in Indonesia. In 2006, this number tripled to 19 million people, and in 2010 increased to approximately 23 million people. ${ }^{(5)}$ It has been predicted that in 2025 and 2050 , the number of elderly in Indonesia will rise to $34,592,000$ and $67,353,000$ people respectively. ${ }^{(5)}$ This will cause a parallel increase in the number of skin-related diseases, especially because older individuals have a thinner stratum corneum, fewer hair follicles, and lower skin hydration level as compared to the younger. ${ }^{(3)}$ Skin dryness may increase TEWL, which in turn will increase skin dehydration. ${ }^{(6)}$

Moisturizers are the most common skincare products that are often used to reduce dryness of the skin by minimizing skin friction, softening the skin, and filling skin cracks. ${ }^{(7)}$ The usage of moisturizers containing vitamin $\mathrm{E}$ for maintaining skin hydration has been well studied. It acts as an antioxidant and inhibits the formation of lipid peroxides, and thus prevents skin aging. ${ }^{(8)}$
Recently, green tea has been introduced as an active component in moisturizers. Both green tea and vitamin $\mathrm{E}$ have antioxidant effects that have been related to delaying the aging process. ${ }^{(9-11)}$ A study showed that green teacontaining cosmetic formulations have pronounced moisturizing effects and skin microrelief improvement. ${ }^{(12)}$

Catechins are the major antioxidants in green tea (Camellia sinensis or Camellia assamica), but since they do not penetrate the skin well, the application of green tea in cosmetic products has so far been limited. ${ }^{(13)}$ A review of numerous studies with green tea (Camellia sinensis) has concluded that both oral consumption and topical application of green tea protect against inflammation, and chemical and UV-induced carcinogenesis. ${ }^{(14)}$

A study to evaluate the human skin penetration of epigallocatechin-3-gallate (EGCG) and quercetin from green tea and Gingko biloba extracts vehiculated in cosmetic formulations showed that both compounds exhibited good skin penetration and retention, which can favor their skin effects. ${ }^{(15)}$

Meanwhile in India, vegetable oils have been used as skin moisturizers, especially in neonates and children due to their proven efficacy, low cost, easy availability and good safety profile. ${ }^{(16)}$ Our study was to evaluate the effectiveness of green tea moisturizer cream in elderly persons, whose skins are dehydrated, making them more sensitive and fragile than young people's. There are promising results with the use of green tea for several dermatologic conditions. ${ }^{(17)}$

However, the efficacy of topical green tea has not always been confirmed. One randomized, double-blind, controlled, clinical trial involving 40 women with moderate photoaging, who were treated with topical green tea extract, showed no statistically significant clinical improvements in these women. ${ }^{(18)}$

This study evaluated the effect of a green tea containing moisturizer on skin hydration in older people. 


\section{METHODS}

\section{Research design}

A quasi-experimental controlled study was conducted amongst elderly living in Tresna Werda Budi Mulia 4 Social Institution, Jakarta, from February 2015 until January 2016.

\section{Research subjects}

All subjects were aged 60 years or above, and included both men and women. The eligibility criteria were absence of dermatitis, erythema, psoriasis, and other skin diseases or tattoos on the arms, and currently not under any local or systemic therapy. Individuals were excluded if they developed any skin allergy or skin disease during the intervention period or if they did not comply with the study protocol. The sample size was obtained using the formula ${ }^{(19)}$

$$
\mathrm{N}_{1}=\mathrm{N}_{2}=2\left[\frac{\left(\mathrm{Z}_{\alpha}+\mathrm{Z}_{\beta}\right) \mathrm{Sd}}{\mathrm{X}_{1}-\mathrm{X}_{2}}\right]^{2}
$$

Where $\alpha=5 \%$, so the $Z_{\alpha}=1.96 ; \beta=20 \%$, so that $Z_{\beta}=0.84$; the mean differenced was 5 . The optimal sample size for each group was 30 .

\section{Intervention}

The participants were randomly allocated to the green tea group and the vitamin E control group. Moisturizers containing green tea or vitamin $\mathrm{E}$ were distributed inside two identical standard containers, weighing 12.5 grams each. Trained caregivers applied the moisturizer on the participant's right and left forearms, twice a day after showering for 5 weeks. Each of the subjects' volar surface of the forearms was divided into three sites, i.e. proximal, medial, and distal, with application area of $2 \times 2 \mathrm{~cm}$ each. Each measurement area was approximately four square centimeters.

\section{Measurements}

The skin hydration level was measured with the Runve HL 611 skin analyzer at baseline and every week during the 5 -week intervention. The skin analyzer had to be placed on the skin with constant pressure until both contacting poles depressed the skin. After three to five seconds, the measurement result would appear on the LCD screen. Treatment application was monitored daily by evaluating the used container and by cross-checking information between the respondents and the field workers. Dropouts were those allergic to any ingredient in the moisturizer, those with skin diseases, severe medical condition, reluctant or incompliant subjects, and participants who passed away during experimental period or transferred to another social institution.

Relative changes in skin hydration were evaluated from the baseline value, and were expressed as percent differences in skin hydration between each week of follow-up and baseline.

\section{Statistical analysis}

To evaluate the repeated measurements, we used the Generalized Estimating Equation (GEE) statistical procedure. Data distribution was found to be normal. Potential confounding factors related to skin hydration were evaluated, such as age; sex; frequency of showering (minimally twice a day); whether subjects had been using other moisturizers, eucalyptus oil, balm or powder; whether any skin disorder was present; and liquid intake (in cups/day). The statistically significant was used at $\mathrm{p}<0.05$.

\section{Ethical clearance}

The study was approved by the Human Subjects Committee of Trisakti School of Medicine 8/KER/FK/V/2015. Each participant had given an informed consent.

At the start of the study 62 subjects were recruited, among whom 60 were found to meet the inclusion and exclusion criteria. During the five-week study period, there were no dropouts. At the end of the study there were 60 remaining subjects, comprising 26 subjects in the green tea group and 36 subjects in the vitamin E group (Figure 1). 


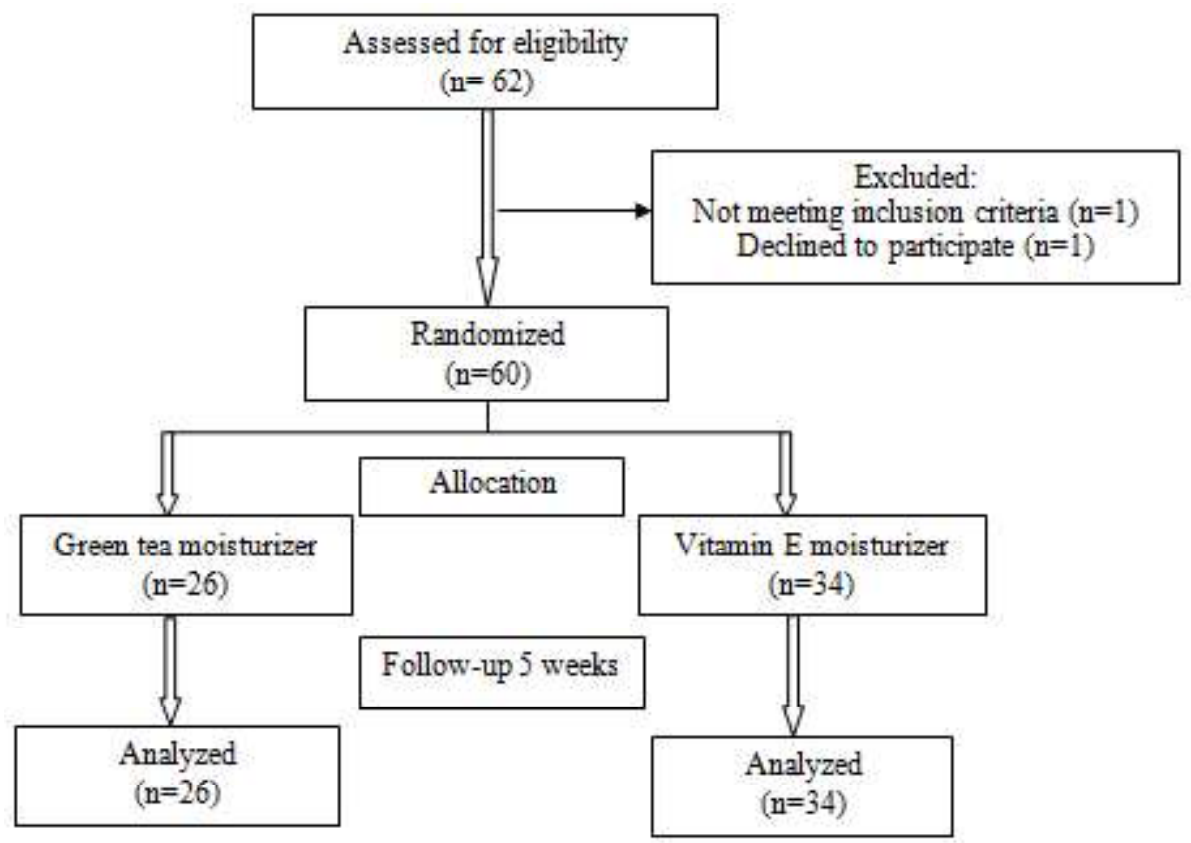

Figure 1. Flowchart of the research subjects

The overall rate of compliance over 5 weeks of intervention was $69.8 \%$ in both groups $(60.5 \%$ in the green tea group, and $79.1 \%$ in the vitamin E group; $p=0.061$ ). Baseline characteristics of the respondents are shown in Table 1. The mean age of the respondents was $75.4 \pm 8.5$ years, and most participants $(73 \%)$ were women. There were no significant skin hydration differences between the groups at baseline, and in some factors that are of potential influence on skin hydration ( $p>0.05)$. The green tea group had a significantly higher relative change of skin hydration than the vitamin

Table 1. Baseline characteristic of the study population

\begin{tabular}{|c|c|c|c|}
\hline & $\begin{array}{c}\text { Green tea moisturizer } \\
(\mathrm{n}=\mathbf{2 6})\end{array}$ & $\begin{array}{c}\text { Vitamin E moisturizer } \\
(\mathbf{n}=\mathbf{3 4})\end{array}$ & p value \\
\hline Age (years) & $71.5 \pm 7.6$ & $70.3 \pm 9.4$ & 0.611 \\
\hline \multicolumn{4}{|l|}{ Sex } \\
\hline Women & $20(76.9)$ & $24(70.6)$ & 0.582 \\
\hline Men & $6(23.1)$ & $10(29.4)$ & \\
\hline Showering min. twice/d & $25(96.2)$ & $32(94.1)$ & 0.731 \\
\hline \multicolumn{4}{|l|}{ Routine application } \\
\hline Moisturizer ${ }^{*}$ & 0 & $3(8.8)$ & 0.251 \\
\hline Eucalyptus oil ${ }^{\dagger}$ & $4(15.4)$ & $5(14.7)$ & 0.944 \\
\hline Balm & $1(3.8)$ & $2(5.9)$ & 0.732 \\
\hline Powder ${ }^{*}$ & $1(3.8)$ & $3(8.8)$ & 0.625 \\
\hline Skin disorders ${ }^{*}$ & $4(15.4)$ & $10(29.4)$ & 0.204 \\
\hline Liquid intakes (cup /d) & $4.7 \pm 2.1$ & $4.2 \pm 2.3$ & 0.381 \\
\hline \multicolumn{4}{|l|}{$\%$ - right arm skin hydration } \\
\hline Proximal & $39.0 \pm 3.87$ & $39.9 \pm 4.56$ & 0.452 \\
\hline Medial & $37.8 \pm 4.39$ & $38.3 \pm 4.59$ & 0.703 \\
\hline Distal & $37.5 \pm 4.29$ & $37.9 \pm 4.24$ & 0.692 \\
\hline \multicolumn{4}{|l|}{$\%$ - left arm skin hydration } \\
\hline Proximal & $39.4 \pm 4.51$ & $39.6 \pm 4.07$ & 0.811 \\
\hline Medial & $38.2 \pm 4.19$ & $38.1 \pm 4.51$ & 0.971 \\
\hline Distal & $38.0 \pm 4.90$ & $38.4 \pm 4.48$ & 0.692 \\
\hline
\end{tabular}

Data presented as mean $\pm \mathrm{SD}$, except for sex, showering, routine application, skin disorders and liquid intakes (n, \%)

$\uparrow$ Differences between the moisturizer groups were calculated by two groups independent $-t$-test (numerical data) or Pearson Chi-square / Fisher exact-test (categorical data) 
Table 2. Relative changes from baseline in skin hydration during 5 weeks of intervention by treatment groups

\begin{tabular}{|c|c|c|c|c|}
\hline & & $\begin{array}{l}\text { Green Tea moisturizer } \\
(\mathrm{n}=26)\end{array}$ & $\begin{array}{c}\text { Vitamin E moisturizer } \\
(\mathrm{n}=34)\end{array}$ & $p$ value \\
\hline \multicolumn{5}{|l|}{ Right Arm } \\
\hline \multirow[t]{6}{*}{ Proximal } & Week 1 & $10.40 \pm 3.16$ & $1.88 \pm 2.84$ & 0.502 \\
\hline & Week 2 & $6.22 \pm 2.29$ & $3.85 \pm 1.95$ & 0.431 \\
\hline & Week 3 & $4.43 \pm 2.64$ & $0.18 \pm 2.37$ & 0.193 \\
\hline & Week 4 & $3.92 \pm 2.89$ & $4.47 \pm 2.53$ & 0.881 \\
\hline & Week 5 & $7.08 \pm 2.97$ & $6.90 \pm 2.36$ & 0.964 \\
\hline & Mean (wk 1 to 5 ) & $5.25 \pm 2.34$ & $2.82 \pm 2.86$ & 0.021 \\
\hline \multirow[t]{6}{*}{ Medial } & Week 1 & $9.16 \pm 2.85$ & $2.50 \pm 2.56$ & 0.082 \\
\hline & Week 2 & $7.84 \pm 2.56$ & $4.58 \pm 2.18$ & 0.341 \\
\hline & Week 3 & $4.42 \pm 3.09$ & $0.16 \pm 2.79$ & 2.282 \\
\hline & Week 4 & $3.55 \pm 2.81$ & $3.61 \pm 2.46$ & 0.981 \\
\hline & Week 5 & $5.28 \pm 2.64$ & $6.35 \pm 2.31$ & 0.763 \\
\hline & Mean (wk 1 to 5 ) & $4.88 \pm 3.37$ & $2.54 \pm 2.40$ & 0.021 \\
\hline \multirow[t]{6}{*}{ Distal } & Week 1 & $9.93 \pm 2.58$ & $0.93 \pm 2.31$ & 0.014 \\
\hline & Week 2 & $7.52 \pm 2.63$ & $4.20 \pm 2.25$ & 0.341 \\
\hline & Week 3 & $5.05 \pm 3.15$ & $1.68 \pm 2.84$ & 0.124 \\
\hline & Week 4 & $0.23 \pm 3.58$ & $3.22 \pm 3.22$ & 0.472 \\
\hline & Week 5 & $5.04 \pm 2.19$ & $6.49 \pm 1.92$ & 0.621 \\
\hline & Mean (wk 1 to 5 ) & $4.32 \pm 3.47$ & $2.27 \pm 2.11$ & 0.021 \\
\hline \multicolumn{5}{|l|}{ Left Arm } \\
\hline \multirow[t]{6}{*}{ Proximal } & Week 1 & $10.24 \pm 3.07$ & $3.17 \pm 2.75$ & 0.092 \\
\hline & Week 2 & $8.14 \pm 2.63$ & $2.99 \pm 2.24$ & 0.143 \\
\hline & Week 3 & $3.97 \pm 2.81$ & $0.03 \pm 2.53$ & 0.302 \\
\hline & Week 4 & $2.96 \pm 2.81$ & $3.71 \pm 2.46$ & 0.841 \\
\hline & Week 5 & $4.89 \pm 2.74$ & $5.77 \pm 2.39$ & 0.812 \\
\hline & Mean (wk 1 to 5) & $4.90 \pm 2.79$ & $2.57 \pm 2.67$ & 0.021 \\
\hline \multirow[t]{6}{*}{ Medial } & Week 1 & $9.04 \pm 2.82$ & $2.83 \pm 2.54$ & 0.111 \\
\hline & Week 2 & $7.66 \pm 2.46$ & $5.01 \pm 2.09$ & 0.421 \\
\hline & Week 3 & $4.37 \pm 3.03$ & $0.26 \pm 2.73$ & 0.324 \\
\hline & Week 4 & $3.36 \pm 2.72$ & $4.09 \pm 2.38$ & 0.842 \\
\hline & Week 5 & $5.37 \pm 2.62$ & $6.82 \pm 2.29$ & 0.681 \\
\hline & Mean (wk 1 to 5 ) & $4.84 \pm 2.90$ & $3.14 \pm 2.59$ & 0.034 \\
\hline \multirow[t]{6}{*}{ Distal } & Week 1 & $7.64 \pm 2.55$ & $0.27 \pm 2.29$ & 0.021 \\
\hline & Week 2 & $4.58 \pm 2.62$ & $0.89 \pm 2.24$ & 0.292 \\
\hline & Week 3 & $0.57 \pm 2.75$ & $3.82 \pm 2.47$ & 0.241 \\
\hline & Week 4 & $1.65 \pm 3.03$ & $1.89 \pm 2.65$ & 0.953 \\
\hline & Week 5 & $2.55 \pm 2.42$ & $2.87 \pm 2.11$ & 0.922 \\
\hline & Mean (wk 1 to 5 ) & $2.71 \pm 2.86$ & $0.32 \pm 2.46$ & 0.021 \\
\hline
\end{tabular}

Data presented as mean $\pm \mathrm{SD}$

E group at all measurement locations $(\mathrm{p}=0.021$ for proximal, medial and distal right arm, and proximal left arm; $p=0.034$ for medial and distal left arm) (Table 2, Figures 1 and 2). Within each of the two groups, skin hydration improved during the 5 weeks of intervention, indicating the presence of a time effect (duration of moisturizer application) in skin hydration changes, especially at the proximal $(\mathrm{p}=0.021)$, medial $(\mathrm{p}=0.006)$ and distal right $\operatorname{arm}(\mathrm{p}=0.006)$, as well as at the medial left arm ( $p=0.021)$. At all measurement sites, we found no correlation between the effects of the moisturizer and the duration of intervention on the relative changes in skin hydration. Both moisturizers showed a parallel trend in the relative change of skin hydration during the 

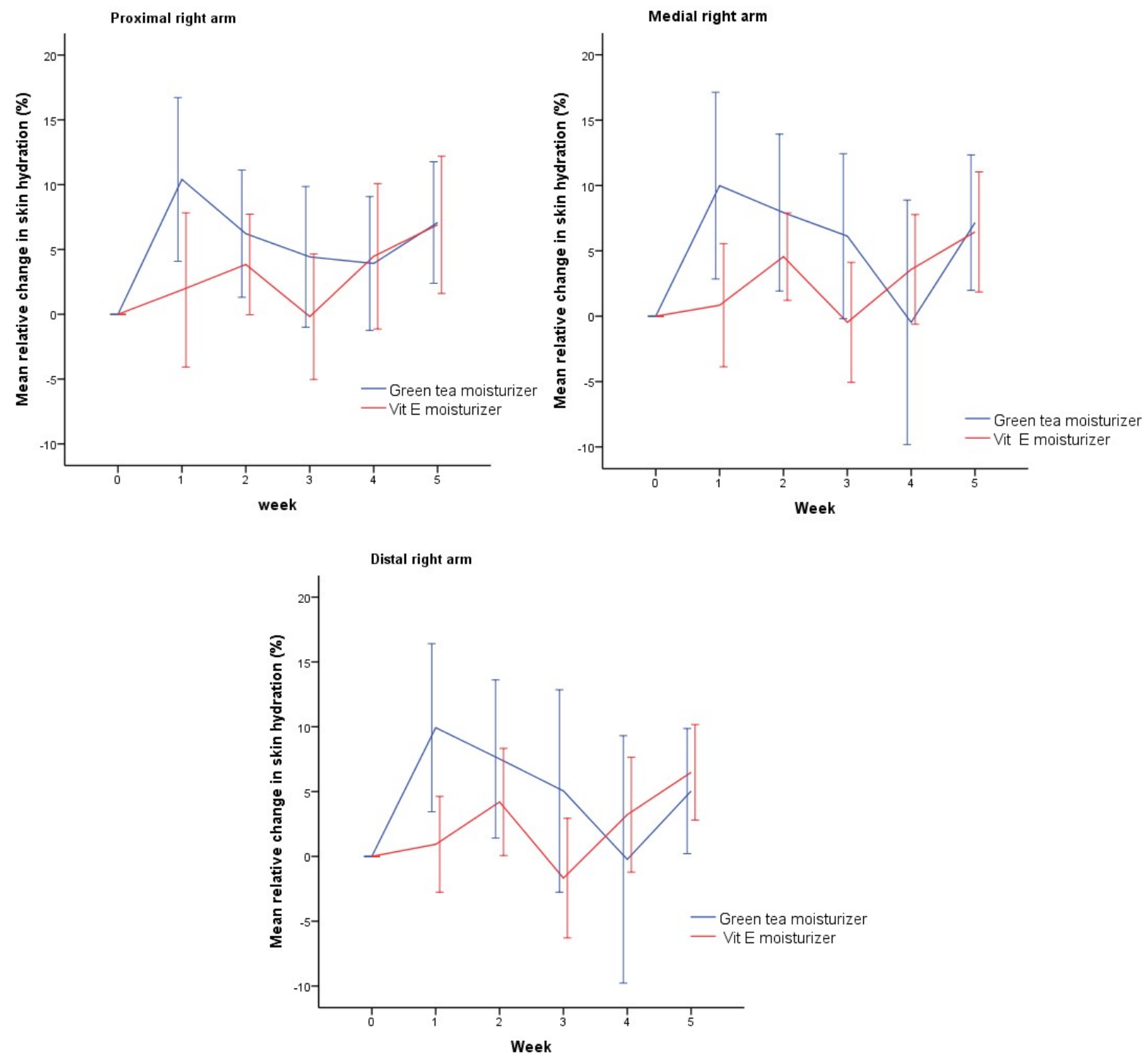

Figure 2. Relative changes of skin hydration of the right arm during 5 weeks of intervention according to moisturizer group

Vertical bars indicate $95 \%$ CI. Mean relative changes in skin hydration are expressed as percentage of the baseline value of the difference between follow-up and baseline values. Changes in skin hydration over time were analyzed using generalized estimating equations.

p group $<0.05$ indicates the group effect (difference between the two groups); $p$ time $<0.05$ indicates the time effect (change within-subject over time) and $p$ group*time indicates group by time interaction (different trend of change over time between the two groups). Results are presented for 60 participants at all- time points (26 in the green tea moisturizer group; and 34 in the vitamin E moisturizer group).

overall 5-week intervention $(\mathrm{p}>0.05$ for the moisturizer and time). Additional adjustments for some factors related to skin hydration did not change overall results. Furthermore, we observed that over the 5-week study period, both groups did not have any objective signs or subjective complaints that might be interpreted as being the side effects of the moisturizer.

\section{DISCUSSION}

This study shows that moisturizer application is crucial for the elderly skin. It prevents pruritus, thus maintaining the highest degree of skin integrity. The elderly tend to acquire a drier skin, therefore proper moisturizer usage is necessary to avoid dry skin-related 

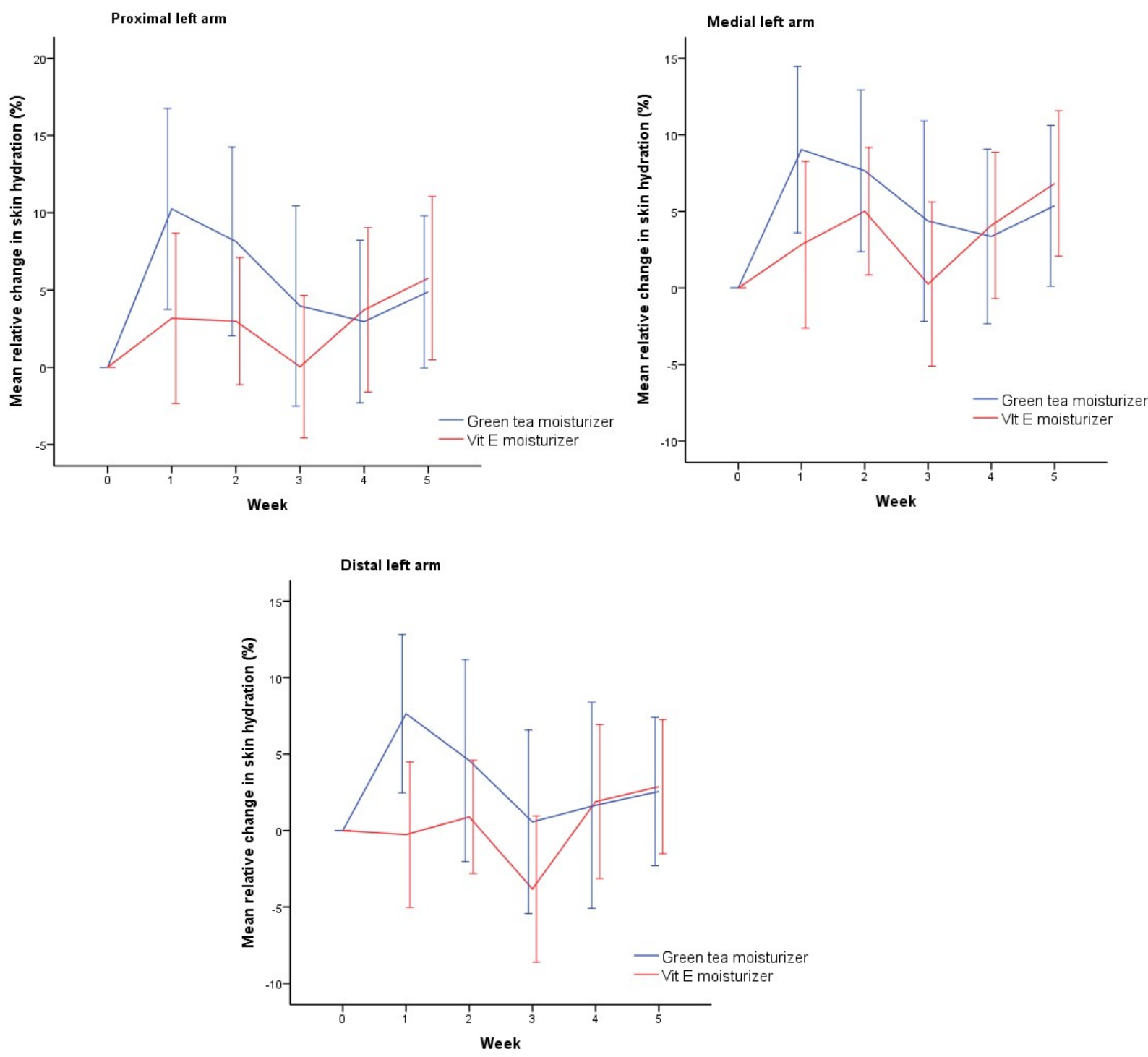

Figure 3. Relative changes of skin hydration of the left arm during 5 weeks of intervention according to moisturizer group Vertical bars indicate $95 \%$ CI. Mean relative changes in skin hydration are expressed as percentage of the baseline value of the difference between follow-up and baseline values. Changes in skin hydration over time were analyzed using generalized estimating equations.

$p$ group $<0.05$ indicates the group effect (difference between the two groups); $p$ time $<0.05$ indicates the time effect (change within-subject over time) and $\mathrm{p}$ group*time indicates group by time interaction (different trend of change over time between the two groups). Results are presented for 60 participants at all- time points ( 26 in the green tea moisturizer group; and 34 in the vitamin E moisturizer group).

problems, such as pruritus. Other studies have also emphasized on improving and maintaining elderly skin hydration with topical or oral supplementations. In their study, Mahmood et al. ${ }^{(16)}$ found that application of the combination of green tea plus lotus extract as moisturizer lead to a greater improvement in skin hydration than did each ingredient alone. In another study, Chiu et al. ${ }^{(18)}$ found that consuming green tea polyphenol with milk is good for the elderly, because catechin from green tea will bind to the milk protein casein and form a catechin-casein complex. The bioavailability of the catechincasein complex in the digestive tract is better than catechin alone, therefore greater absorption levels of the antioxidant will be achieved. This antioxidant is crucial for skin integrity. A study by Lee at al. ${ }^{(19)}$ on Asian female subjects aged 
32-56 years discovered that fermented green tea consumption has a cooling effect on women's peripheral skin temperature, which is useful for people with cold hypersensitivity. These studies were similar to our study in their objective, which was to maintain skin hydration in order to keep the skin barrier intact. However, they slightly differ from our study in the methods used, the longer-term study design, and the use of more advanced measuring equipment.

With increasing age and presumably also aging process, the need for moisturizer application increases. Our study showed that among 60 participants, approximately only $2.3-7.0 \%$ had been using moisturizers before this study was conducted. Skin disorders were found in $20.9 \%$ of participants in both groups such as atopic dermatitis, chronic lichen simplex, scabies, ichthyosis, and tinea corporis. In subjects with skin disorders, the measurement was still done at the three locations (proximal, medial, distal), because the results showed that the skin hydration level between both arms at the three locations were not significantly different at baseline.

As an anti-aging substance, vitamin $\mathrm{E}$ has proved to be a stable, easy to formulate, and reasonably priced emollient. Vitamin E acts as an antioxidant substance that prevents lipid peroxidase activities in cells and soft tissues, skin softening, and that reduces inflammation caused by reactive oxygen species, as well as being a topical skin photoprotective. ${ }^{(20)}$ Vitamin E as alpha tocopherol or tocopherol acetate is also used in over-the-counter drugs in $1-5 \%$ concentrations to hydrate the stratum corneum and increase the water binding capacity of the skin. ${ }^{(20,21)}$

Green tea leaves contain around 30-35\% polyphenols, which comprise a number of catechins (flavan-3-ols). Catechins consist of 4 main components, i.e. epicatechin (EC), epigallocatechin (EGC), epicatechin gallate (ECG), and epigallocatechin gallate (EGCG). Epigallocatechin gallate is the most effective antioxidant component among the four types mentioned and protects the skin from photocarcinogenesis and UV-induced phototoxicity, ${ }^{(22-24)}$ and also reduces skin hyperpigmentation. ${ }^{(25)}$ Polyphenols in green tea may inhibit the activity of collagenase and increase the biosynthesis of collagen in fibroblasts to further protect the skin from free radicals..$^{(9,26,27)}$

Moisturizers protect the skin through occluding the TEWL process by creating a protective layer above the stratum corneum. Another mechanism is by increasing water absorption into the stratum corneum (humectant), and filling the gap between desquamating keratinocytes to create a softer skin (emollient). Moisturizers also act as protein rejuvenator to improve the water storage of the epidermis. ${ }^{(2,7)}$

Our clinical trial showed that both vitamin $E$ and green tea extract may be used as an active component of moisturizers, as both substances may act as an antioxidant in moisturizers and in anti-photoaging. The latter further reduces UV exposure that may lead to dry skin.

Between the two study groups, no statistically significant difference was observed. The two groups applied the moisturizer after showers, twice daily. Strict surveillance was done by the field officer because most of the subjects were elderly, who presumably have some degree of memory impairment. The application of the moisturizers by the field workers was monitored by measuring the remaining amount of each moisturizer by the end of the week. Daily application by the field workers and subject compliance were important aspects in this study, since the moisturizers require regular usage in order to achieve a good skin hydration status. Under-treatment of dry skin may give rise to multiple skin disorders, and the resulting itch may cause the patient to scratch, causing secondary skin infections. The management principle of dry skin is to restore the integrity of the stratum corneum, and application of moisturizers may help improving skin hydration status, especially in the elderly. Moisturizers act as occlusive, humectant, and emollient substances that improve the water content of the stratum corneum. ${ }^{(2,4)}$ 
In our study, no side effects were observed following application of either moisturizer to the study participants. There were no objective side effects such as mild erythema and allergic reactions by the second and fifth week after the initiation of intervention. Subjective side effects such as itch, pain, or stinging sensation were also not reported. This result showed that it is safe to apply moisturizer containing either vitamin $\mathrm{E}$ or green tea extract.

Since in practice the subjects had to apply the moisturizer by themselves, personal compliance is very important. Significant moisturization effects can only be achieved with regular usage. One experimental study showed that low compliance reduces the effectivity of moisturizers in improving skin hydration status. ${ }^{(20)}$ In our study, the compliance status of the study participants was associated with improvement of skin hydration status in both groups. On the other hand, incompliance of several subjects and the significant number of drop-outs were identified as the limitation of this study. The study aimed to educate and persuade the elderly to apply moisturizers to keep their skin hydrated. Further studies in the future should utilize a better skin analyzer, in order to obtain more specific and standardized data.

\section{CONCLUSION}

This research suggests that routine use of moisturizers improves skin hydration in the elderly. This effect may be more prominent with the usage of moisturizers containing green tea as compared to those containing vitamin $\mathrm{E}$.

\section{CONFLICT OF INTEREST}

The authors have no conflict of interest.

\section{AKNOWLEDGEMENTS}

The authors are thankful to Irene Dorthy, MD, Sheilla Khonada, S.Ked, Jonathan, S.Ked, and Andy, S.Ked.

\section{CONTRIBUTORS}

LJW conception and design of study, OT acquisition of data and drafting the manuscript, MER analysis and interpretation of data. All authors read and approved the final manuscript.

\section{REFERENCES}

1. Baroni A. Epidermal barrier function: clinical implications and therapeutic. Clin Dermatol 2012; 30:255-366.

2. Del Rosso JQ. Moisturizer and barrier repair formulations. In: Draelos ZD, Dover JS, Alam M, editors. Cosmeceuticals. $3^{\text {rd }}$ ed. Philadelphia: Elsevier;2016.p.81-9.

3. Chu DH. Development and structure of skin. In: Wolff K, Katz S, Paller A, et al, editors. Fitzpatrick's Dermatology in General Medicine. $8^{\text {th }}$ ed. New York: McGraw-Hill; 2012.p.58-75.

4. Draelos ZD. New treatments for restoring impaired epidermal barrier permeability: Skin barrier repair creams. Clin Dermatol 2012;30:345-8.

5. Badan Pusat Statistik. Proyeksi penduduk Indonesia 2010-2035. Jakarta: Badan Pusat Statistik Indonesia;2013.

6. Verdier-Sevrain S, Bonte F. Skin hydration: a review on its molecular mechanisms. J Cosmet Dermatol 2007;6:75-82.

7. Loden M. Effect of moisturizers on epidermal barrier function. Clin Dermatol 2012;30:286-96.

8. Datta HS, Mitra SK, Paramesh R. Theories and management of aging: Modern and Ayurveda perspectives. Evid Based Complement Alternat Med 2011;528527:1-6.

9. Sandeep K, Nisha S, Schweta, et al. Green tea polyphenols: versatile cosmetic ingredients. IJARPB 2012;1:348-62.

10. Lintner K, Mas-Chamberlin C, Mondon P, et al. Cosmeceuticals and active ingredients. Clin Dermatol 2009;27:461-8.

11. Chanchal D, Swarnlata S. Novel approaches in herbal cosmetics. J Cosmet Dermatol 2008;7:8995.

12. Gianeti MD, Mercurio DG, Campos PM. The use of green tea extract in cosmetic formulations: not only an antioxidant active ingredient. Dermatol Ther 2013;26:267-71.

13. Wisuitiprot W, Somsiri A, Ingkaninan K, et al. In vitro human skin permeation and cutaneous metabolism of catechins from green tea extract and green tea extract-loaded chitosan microparticles. Int J Cosmet Sci 2011;33:572-9. 
14. Binic I, Lazarevic V, Ljubenovic M, et al. Skin aging: natural weapons and strategies. Evid Based Complement Alternat Med 2013; 827248:110.

15. Belo SE, Gaspar LR, Maia Campos PM, Marty JP. Skin penetration of epigallocatechin-3-gallate and quercetin from green tea and ginkgo biloba extracts vehiculated in cosmetic formulations. Skin Pharmacol Physiol 2009;22:299-304.

16. Sarkar R, Podder I, Gokhale N, et al. Use of vegetable oils in dermatology: an overview. Int $\mathrm{J}$ Dermatol 2017;56:1080-6.

17. White PO, Tribout H, Baron E. Protective mechanisms of green tea polyphenols in skin. Oxidative Med Cell Longevity 2012, Article ID 560682, 8 pages. doi: 10.1155/2012/560682.

18. Chiu AE, Chan JL, Kern DG, et al. Double blinded,placebo-controlled trial of green tea extracts in the clinical and histologic appearance of photoaging skin. Dermatol Surg 2005;31:85560.

19. Sudigdo S, Sofyan I. Dasar-dasar metodologi penelitian klinis $4^{\text {th }}$ ed. Jakarta: Sagung Seto;2011.

20. Mahmood T, Akhtar N. Combined topical application of lotus and green tea improves facial skin surface parameters. Rejuvenation Res 2013; 16:91-7.
21. Chiu HF, Lin TY, Shen YC, et al. Improvement of green tea polyphenol with milk on skin with respect in healthy adults: a double-blind placebocontrolled randomized crossover clinical trial. Food Funct 2016;7:893-901.

22. Lee E, Lee BJ, Ha J, et al. Efficacy of fermented green tea on peripheral skin temperature: a randomized and placebo-controlled clinical study. J Cosmet Dermatol 2016;15:226-30.

23. Thiele JJ, Ekanayake-Mudiyanselage S. Vitamin $\mathrm{E}$ in human skin: organ-specific physiology and considerations for its use in dermatology. Mol Aspects Med 2007;28:646-67.

24. Baumann L. Tocopherol (vitamin E). In: Weisburg E. Cosmeceuticals and cosmetic ingredients. New York: McGraw-Hill;2014.p.182-7.

25. Baumann L. Green tea. In: Weisburg E. Cosmeceuticals and cosmetic ingredients. New York: McGraw-Hill;2014.p.137-43.

26. Zink A, Traidl-Hoffmann C. Green tea in dermatology - myths and facts. J Dtsch Dermatol Ges 2015;13:768-75.

27. Yusuf N, Irby C, Katiyar SK, et al. Photoprotective effects of green tea polyphenols. Photodermatol Photoimmunol Photomed 2007;23:48-56. 